\title{
Treating offenders with personality disorder
}

Tony Maden

While carrying out research in a special hospital, I encountered a small group of middle-aged patients who spent most of their time engaged in sporting activities. They had considerable freedom within the high security perimeter, and were regarded as presenting no risks, as long as they had no access to children. All were detained under the legal category of psychopathic disorder, and none of them were receiving psychiatric treatment, unless the term milieu therapy were to be stretched to include a patient's mere presence within a hospital. Their past offences were such as to lead to a shared understanding that they were unlikely ever to be released, and a compromise had been reached. The patients were aware that they enjoyed a quality of life that was as good as they could expect in the circumstances. The hospital accepted that it would have the patients for as long as their restriction orders lasted, and saw itself as providing a valuable public service by keeping them locked up.

From a purely pragmatic viewpoint, there was much to recommend this arrangement. Society was being protected, and individuals who were locked up partly because of their sexual preference (which they did not choose) were not being punished unduly. From most other viewpoints, the situation was indefensible. Others can express the powerful legal and ethical arguments; I would like to concentrate on the medical aspects. It makes no sense for a hospital bed to be occupied by a person who is not receiving medical treatment, purely to protect society from a high risk of offending. It is entirely reasonable that society should wish to protect its members, but it is not a job for a hospital, or for medical staff. Apart from the waste of resources, it contaminates the institution, breeds a nihilistic, custodial ethos and so damages other patients who are receiving treatment.

This is an historical anecdote, and I am sure there are no patients of this type in psychiatric hospitals today. Nevertheless, there is an important message for psychiatry. Nobody believes that doctor knows best any more, and medical practice is facing unprecedented public scrutiny, sometimes concerned with the smallest of clinical details. This scepticism about medical motives applies to all specialities, including surgery. It is bound to be applied with even greater force to psychiatry, which did not enjoy high public regard in the first place. As clinical governance forces us to examine the efficacy of all our treatments, they will have to be justified in a forum where difficult questions cannot be avoided.

\section{Definitions and selection for treatment}

The definition of psychopathic disorder is purely legal. This disease exists only in the Mental Health Act 1983, and does not correspond to any medical diagnosis. There is overlap with several categories of personality disorder, so that all persons who fit the legal definition should fulfil the diagnostic criteria for at least one of these disorders, but the reverse is not true. Most of those with a personality disorder, even in populations of offenders, are not considered to be suffering from psychopathic disorder.

A recent survey by the Office for National Statistics (Singleton et al, 1999) diagnosed personality disorder in $64 \%$ of male sentenced prisoners, and $78 \%$ of male remand prisoners. Only a handful of prisoners on remand will be considered for hospital orders under the psychopathic disorder category, raising the suspicion that selection for treatment is arbitrary. Critics have argued that spurious factors determine selection, including the notoriety of the offence, the degree to which the case is bizarre or 'interesting', and the identity of the assessing doctor (Dell \& Robertson, 1988). The profession has no data with which to counter these accusations.

Of course, there may be many reasons why a treatment offered to many is taken up by only a few of those who could benefit. Problems arise when the treatment is imposed, rather than offered. The individual is forced to demonstrate improvement, according to criteria which he may neither understand nor accept, if he is ever to be released. These difficulties are compounded by confusion over definitions, on the part of mental 
health review tribunals and those writing reports. Some see psychopathic disorder as being synonymous with one or other personality disorder, as defined in ICD-10 (World Health Organization, 1992). These definitions are inherently unsatisfactory, as the presence of a disorder of mind is inferred from a history of deviant behaviour alone. This is a dubious basis on which to justify indeterminate detention, as the historical nature of the label means that it is difficult ever to lose it. The over-inclusive nature of the definitions in ICD-10 means that most offenders would be detainable, if personality disorder in combination with offending is seen as the equivalent of psychopathic disorder.

Practical problems arise because there is a vast range of attitudes towards those with psychopathic disorder, even within the tiny discipline of forensic psychiatry. We may regret the existence of such discord, but it cannot be ignored, and it would be irresponsible to attempt to do so. The consequences for the individual patient are horrifying. He may be detained in hospital by two doctors who believe that society will be protected, and his own mental health improved, after spending several years in that setting. It is possible, indeed likely, that he will be 'treated' by a doctor who does not believe that treatment is appropriate. His doctor may believe that treatment cannot change his fundamental nature which is inevitably viewed in very negative terms. This is unfair and indefensible.

Of course, some offenders pose a risk because of their abnormal personalities or sexual perversions, and it is reasonable that society should seek to restrict their liberty until their problems have been addressed. There are many ways of achieving this aim, without resort to the hospital order.

\section{'Treatability'}

This concept generates heated arguments within psychiatry and is central to understanding the problem of psychopathic disorder and its treatment. The Mental Health Act speaks of a likelihood that treatment will alleviate or prevent deterioration in the patient's disorder, but the term 'treatability' is widely used as shorthand. It is ironic that this clause, inserted into the Mental Health Act 1983 to prevent the indefinite detention in hospital of those who could not benefit from treatment, should have been perverted to deny treatment to individuals who may request it.

The concept of treatability grew out of a concern for civil liberties, and the case for safeguards against the indefinite, compulsory hospitalisation of those who cannot benefit from treatment is a strong one. The crucial aspect is detention for treatment against the patient's will. 'Treatability' makes less sense as a selection criterion, once treatment is voluntary. Restriction of voluntary treatment is simply a question of rationing. We recognise that resources should not be wasted by treating those who derive no benefit, but we are slow to reject any patient completely. The term 'incurable' is rightly seen as pejorative, and a vast range of rehabilitative or palliative services are available for diseases or disabilities which have no cure. Treatmentresistant schizophrenia is a classic example of an 'untreatable' disease, yet there is no call for the rejection of patients with this label.

The refusal to help patients who are acknowledged to have a disease, just because they are unlikely to get better, violates all of medicine's ethical principles. It is also bad science in that medical progress would be impossible if doctors washed their hands of every disease for which the treatment is uncertain. The damage caused by this attitude should not be underestimated. There are few more depressing sights than the complacency with which some psychiatrists will diagnose an untreatable personality disorder, conclude that supervision is impossible - then leave a probation officer to carry out the supervision.

So long as this attitude persists, psychiatry will find it difficult to justify its call upon resources, as a public service. Worse still, it is difficult to see how forensic psychiatry can remain as a branch of medicine, if it adopts a different set of ethical principles, whose loftiest aim is self-protection for doctors.

These are severe and fundamental problems and it seems obvious that the concept of 'treatability' must go, before irreparable damage is done to psychiatry's public standing. The inevitable consequence is that the compulsory detention of personality disordered patients on hospital orders must also be ended. It is impossible to continue such a practice without selecting out those who are not treatable, but a branch of medicine cannot afford to use such a criterion. Of course, many offenders with personality disorders would be detainable because of symptoms of mental illness, but the abnormality of personality alone should not be sufficient reason.

\section{Voluntary treatment and coercion}

Convicted offenders have restrictions placed on their liberty and it seems reasonable that, when problems are identified as contributing to future risk, the relaxation or ending of restrictions should be tied to the offender's demonstration that these problems have been addressed. Doctors in this country have always been 
squeamish about coercion, and developments of such programmes for drug misusers are less advanced than in some parts of the USA. The reservations are easily understood as convenient for doctors (we would all prefer to have patients who are willing, enthusiastic and grateful) but the moral objections are unconvincing. These forms of treatment are increasing, as the following three examples show.

\section{Sex offender treatment programmes}

These programmes are mandatory for certain categories of prisoner, and performance within the programme has a bearing on applications for early release (Thornton \& Hogue, 1993). Psychologists play a central role in these programmes within prison. Outside, there are an increasing number of programmes operated by probation services. Attendance may be a condition of avoiding a prison sentence, or a condition of early release from prison.

\section{H. M. P. Grendon}

This is the best known of the therapeutic communities within prison, and a similar facility is being developed in Staffordshire. The regime is operated by prison officers, and inmates are able to return to the ordinary prison system if they wish (Genders \& Player, 1989).

\section{Discretionary 'lifers'}

In some serious offences other than murder, a life sentence can be given at the judge's discretion. The discretionary life sentence is used to protect the public, and implies that the offender is considered dangerous. Psychiatric reports are usually included in the evidence on which the decision is based and it is common for such reports to 'diagnose' psychopathic disorder which is not likely to respond to treatment (Smith, 1998).

After sentencing, the prisoner serves a tariff, the number of years deemed necessary for the purposes of retribution and deterrence. From that point onwards, applications for release on license are considered by the parole board, and are determined entirely by the risk to the public. The dossier considered by the parole board includes reports from various disciplines, all addressing the question of risk. Release may depend on explicit treatment, or there may be a developing of self-awareness through interactions with staff and other inmates, within the ordinary prison regime. Recent legislation (the Crime Sentences Act 1997) has increased pressure on judges to give life sentences, and this part of the prison population will continue to grow.
Discretionary lifers are an important group for psychiatry, as they are similar in many ways to those patients who receive a hospital order with restrictions, under the legal category of psychopathic disorder. The challenge for psychiatry is to produce evidence that it can do better with this group than the discretionary lifer system. While it is coercive, this system allows prisoners a degree of choice which is not available to those on hospital orders. Psychiatry must justify its decision to remove that element of choice, by better or quicker results. It must then present a convincing case in terms of health economics, for spending money on this type of treatment rather than on other health services. In the absence of any such evidence, it is difficult to justify the use of hospital orders. After all, transfer to hospital for treatment remains an option for all mentally disordered prisoners.

\section{Psychiatry and coercion}

In general, psychiatry has little input into the interventions described above. In the case of discretionary lifers, it is depressingly common to find that the shortest report in the bundle of parole board papers is that by the psychiatrist, who has met the prisoner only briefly, for the purpose of writing the report. It is a common complaint of probation officers in some parts of the country, that they are left to struggle with the most high-risk individuals, without the benefit of psychiatric assistance.

The usual reason given by psychiatrists for their lack of involvement is that the individual is not treatable. This is a foolproof get-out clause, as it has no agreed meaning. We turn a blind eye to the fact that many of these individuals go on to receive from a probation officer, psychologist or prison officer, something that would be called treatment if it were given by a doctor.

\section{Preventive detention}

After a long absence, preventive detention is back on the criminal justice system's agenda (Home Office, 1996). The Criminal Justice Act 1991 provides for increased sentences for sexual and violent offenders when necessary to protect the public from serious harm (Solomka, 1996). The Crime Sentences Act 1997 requires that courts impose a life sentence for a second serious offence, unless there are important reasons for not doing so. In some ways, this is more draconian than California's 'three strikes and out' approach, but these subtle differences are peripheral to the present argument. In many countries, there is a movement away from the principle that the sentence should fit the crime (the 'just desserts' model), to emphasise the 
other functions of sentencing, for instance, deterrence and protection of the public.

Whatever one's views of this legislation, it is popular, and the principle of sentencing in order to protect the public is sound. The objections are pragmatic. The ability to predict future offending is limited, so how can it provide a basis for such prolonged restriction of liberty? The legislation side-steps this issue, by relying solely on the offences of which a person has been convicted. There may be a lack of fairness in this rigid approach, but it has the advantage of clarity, and is surely no more unfair than the arbitrary system which determines whether or not persons with psychopathic disorder receive a hospital order. Given the spectrum of opinion within psychiatry, most defendants would be better off with the discretionary life sentence.

\section{Comment}

From a pragmatic viewpoint, psychiatry cannot afford to go on detaining people on hospital orders, on the grounds of an abnormality of personality alone. The divergence of opinion within the profession makes this practice unacceptable, and an obsession with treatability weakens our claim to remain as a branch of medicine. We should pursue medical priorities, including the development and testing of a range of therapeutic interventions aimed at addressing personality disorders and sexual offending. These techniques must be suitable for application within a variety of settings, ranging from voluntary treatment of a person who has never been convicted, to the treatment of a prisoner whose release will depend on demonstrating success.
Psychiatry can still make its contribution to treatment but should take a secondary role when deciding on questions of release or further detention. The chief function of psychiatry is the treatment of mental disorder, with public protection an important but distant second. While doctors must advise and assist courts and parole boards, it is absurd to claim that medicine can beat the criminal justice system at its own game of public protection.

\section{References}

DeLL, S. \& Robertson, G. (1988) Sentenced to Hospital. Maudsley Monograph No. 32. Oxford: Oxford University Press.

Genders, E. \& Player, E. (1989) Grendon. A Study of A Therapeutic Community Within the Prison System. London: Home Office.

HOME OFFice (1996) Protecting the Public. London: HMSO.

Singleton, N., Meltzer, H. \& Gatward, R. (1999) Psychiatric Morbidity Among Prisoners in England and Wales. London: The Stationery Office.

SmrT, A. (1998) Psychiatric evidence and discretionary life sentences. Joumal of Forensic Psychiatry, 9, 17-38.

SOLOMKA, B. (1996) The role of psychiatric evidence in passing longer than normal sentences. Journal of Forensic Psychiatry, 7, 239-155.

THORNTON. D. \& HoGUE. T. (1993) The large-scale provision of programmes for imprisoned sex offenders: issues. dilemmas and progress. Criminal Behaviour and Mental Health, 3, 371-380.

WORLD HEALTH ORGANIZATION (1992) International Classification of Diseases and Related Disorders. (ICD-10). Geneva: WHO.

Tony Maden, Senior Clinical Lecturer, Department of Forensic Psychiatry, Institute of Psychiatry, De Crespigny Park, Denmark Hill. London SE5 8AF 